\title{
DIREITOS HUMANOS DAS MULHERES E INTERSECCIONALIDADES: A IMPORTÂNCIA DE UMA ABORDAGEM ANTIRACISTA E FEMINISTA PARA COMPREENDER A VIOLÊNCIA FEMINICIDA CONTRA \\ MULHERES NEGRAS
}

Elita Isabella Morais Dorvillé de Araújo ${ }^{1}$

Elaine Pimentel ${ }^{2}$

\section{Introdução}

É longo e complexo o caminho de reconhecimento dos direitos humanos das mulheres em todo o mundo. A condição feminina, em toda a história da humanidade, varia de acordo com o tempo e o lugar, de tal forma que construir um conjunto de direitos aptos a abranger todos os aspectos multiculturais que circundam as vidas das mulheres consiste em desafio ainda por ser vencido. Entretanto, seja qual for o momento histórico ou o país de origem, é possível perceber que as diversas formas de opressão e violência praticadas contra as mulheres levaram à construção de uma espécie de consenso humanitário, apontando para a necessidade de positivação, na legislação internacional, da igualdade formal entre homens e mulheres, como passo fundamental para a concretização da igualdade nas relações sociais e, assim, para o enfretamento às violências de gênero.

\section{A Declaração Universal dos} Direitos Humanos, de 1948, representou um marco na defesa da dignidade humana no mundo. Fruto do póssegunda guerra mundial, a Declaração

\footnotetext{
${ }^{1}$ Advogada e Mestranda em Direito Público da Universidade Federal de Alagoas (UFAL) na linha de pesquisa Criminologia, Política Criminal e Direitos Fundamentais. Membro do Núcleo de Estudos sobre Violência em Alagoas - NEVIAL e do Núcleo de Estudos de Políticas Penitenciárias - NEPP da UFAL. Email: isabelita_morais@hotmail.com.

2 Doutora em Sociologia pela Universidade Federal de Pernambuco. Mestra em Sociologia pela Universidade Federal de Alagoas. Professora dos Cursos de Graduação e Mestrado em Direito da Universidade Federal de Alagoas. Líder dos grupos de pesquisa Núcleo de Estudos e Políticas Penitenciárias (NEPP) e CARMIM Feminismo Jurídico, Vice-líder dos grupos de pesquisa Núcleo de Estudos sobre a Violência em Alagoas (NEVIAL) e Grupo de Pesquisa Educações em Prisões (GPEP), todos registrados no CNPq.
} 
elenca princípios e delineia direitos em um momento histórico de especial construção dos direitos humanos, depois dos horrores da guerra e com as marcas profundas deixadas pelas violações à dignidade de homens e mulheres, especialmente nos países que viveram o nazismo.

O $\operatorname{artigo} 7^{\circ}$ da Declaração Universal teve uma função fundamental, ao estabelecer de maneira formal a igualdade de direitos entre todos os indivíduos, sem quaisquer distinções, apontando para a necessidade de proteção concreta contra toda e qualquer forma de discriminação. Tornou-se, então, princípio norteador e base fundamental para a equiparação de gênero em várias constituições modernas.

O presente artigo tece considerações acerca da positivação dos direitos das mulheres nas normas humanitárias internacionais e brasileiras, a partir de uma perspectiva antirracista e feminista, reconhecendo a necessidade de uma interpretação interseccional sobre os direitos humanos, para a análise

3 IPEA, Instituto de Pesquisa Econômica Aplicada; FBSP, Fórum Brasileiro de Segurança Pública. Atlas da violência 2018. Rio de Janeiro, das muitas formas de violência contra as mulheres e em especial do feminicídio. Nesse sentido, apresenta dados do Instituto de Pesquisa Econômica Aplicada (IPEA) e do Fórum Brasileiro de Segurança Pública ${ }^{3}$ sobre a violência de gênero, para problematizar as lacunas existentes na legislação sobre direitos humanos, diante da realidade de mulheres negras, principais vítimas de feminicídios no país.

Pretende-se estabelecer uma crítica à forma tímida como a questão racial aparece no campo dos direitos humanos das mulheres, alertando que, para enfrentar a complexa realidade de violência vivenciada pelas mulheres negras no Brasil e no mundo, é preciso um comprometimento com respostas às discriminações presentes nas vidas dessas mulheres. Nesse sentido, é apresentada a perspectiva da interseccionalidade, na tentativa de demonstrar a necessidade de ampliar os horizontes de reflexão sobre as diversas formas de opressão sofrida pelas mulheres negras, considerando gênero, raça e classe como elementos

junho de 2018. Disponível em: http://www.ipea.gov.br/portal/index.php?option $=$ com_content $\& v i e w=$ article $\& i d=33410 \&$ Itemi $\mathrm{d}=432$. 
indissociáveis da análise social sobre a

violência contra as mulheres.

A Declaração de 1948 da ONU

As considerações aqui inspirou uma maior fluidez e amplitude apresentadas acerca dos direitos humanos das mulheres e sua interpretação encontram esteio no feminismo negro e marginal especialmente nos escritos de Kimberle Crenshaw $^{4}-$ e resultam dos questionamentos que historicamente as feministas negras desenvolveram sobre as teorias feministas, cuja visão universalista dos sujeitos sociais mulheres torna invisíveis as experiências de discriminação e violência vivenciadas pelas mulheres negras. Consequentemente, constrói-se uma crítica à própria perspectiva universalista de direitos humanos, que tende a negar o racismo vivenciado por negras e negros, com repercussão direta sobre a violência letal sofrida.

Direitos Humanos E Universalismos: Construindo Um Conceito Interseccional E Multicultural

\footnotetext{
${ }^{4}$ CRENSHAW, Kimberle. Documento para o encontro de especialistas em aspectos da discriminação racial relativos ao gênero. Rev. Estud. Fem. 2002, vol.10, n.1. Disponível em: http://www.scielo.br/scielo.php?pid=S0104026X2002000100011\&script=sci_abstract\&tlng $=\mathrm{pt}$.
} para a definição de direitos humanos, embora essa interpretação não tenha se dado de maneira a expandir os próprios direitos das mulheres pelo mundo naquele contexto histórico específico. No entanto, o princípio da igualdade entre os gêneros, ou seja, da igualdade de direitos e deveres entre homens e mulheres, teve sua gênese e seu desenvolvimento a partir do que foi positivado pela Declaração de 1948, resultado dos esforços dos movimentos feministas em todo o mundo, "cujas propostas críticas sedimentaram uma radical transformação cultural e epistemológica", segundo Malena Costa. $^{5}$

Os direitos humanos das mulheres foram positivados na ordem jurídica internacional por meio de um processo transformador, resultado do ativismo político e social dos movimentos feministas no mundo.

\footnotetext{
5 COSTA, Malena. Feminismos juridicos. Ciudad Autonoma de Buenos Aires: Didot, 2016, p. 11 .
} 
Foram as exigências das feministas que chamaram a atenção para as desigualdades de gênero que vão além da dimensão meramente formal e se materializam nas desigualdades da vida social. Portanto, pode-se dizer que as discussões sobre o princípio da igualdade entre os gêneros nos tratados internacionais e até mesmo na própria Declaração Universal dos Direitos Humanos tiveram como seu principal combustível, para além da defesa dos direitos humanos no pós-segunda guerra mundial, a pressão política exercida pelos movimentos feministas.

A Declaração da ONU tornou-se, então, um dos marcos propulsores das discussões sobre a questão de gênero no mundo, o que possibilitou a inclusão da igualdade entre homens e mulheres em muitos tratados de direitos humanos e nas Constituições de diversos países, fortalecendo, assim, o ativismo político dos próprios movimentos feministas.

As articulações políticas das mulheres e as muitas teorias feministas construídas a partir das práticas sociais

6 MIGUEL, Luis Felipe; BIROLI, Flávia. Feminismo e política: uma introdução. 1.ed. São Paulo: Boitempo, 2014. p.8.

7 MENDES, Soraia da Rosa. Criminologia Feminista: novos paradigmas. $2^{\circ}$ ed. - São Paulo: Saraiva, 2017, p. 158.
66

foram os responsáveis por novos paradigmas nas ciências, subvertendo a ordem dos modelos tradicionalmente androcêntricos, inclusive nas discussões sobre direitos humanos e sua universalidade. Subverter a ordem do discurso, para os movimentos feministas, significa, portanto, trazer para o centro da questão a compreensão de que o gênero deve ser um dos eixos centrais que organizam as experiências do mundo social ${ }^{6}$.

Soraia da Rosa Mendes, ao falar sobre epistemologia feminista na análise criminológica, num contexto de crítica ao sistema de justiça penal, defende a necessidade de um giro epistemológico a partir de um olhar feminista, em que se observe a realidade concreta vivida pelas mulheres $^{7}$, ou seja, um conjunto de saberes que possam colocar as mulheres como centro da análise, permitindo, diante de pressupostos androcêntricos, um saber construído, necessariamente, a partir das teorias feministas ${ }^{8}$.

Para a feminista negra Kimberle Crenshaw, no contexto da proteção aos

${ }^{8}$ CAMPOS, Carmen Hein de. Criminologia Feminista: Teoria feminista e crítica às criminologias. $1^{\circ}$ ed. - Rio de Janeiro: Lumen Juris, 2017, p. 11. 
direitos humanos sem distinção, "os direitos das mulheres e as circunstâncias específicas em que essas sofrem abusos foram formulados como sendo diferentes da visão clássica de abuso de direitos humanos e, portanto, marginais dentro de um regime que aspirava uma aplicação universal." " Isso porque o universalismo

fundamenta-se firmemente nas experiências dos homens, de modo que "a proteção dos direitos humanos das mulheres foi comprometida à medida que suas experiências poderiam ser definidas como diferentes das dos homens". ${ }^{10} \mathrm{Em}$ outras palavras, as violações aos direitos humanos das mulheres só eram reconhecidas quando se aproximavam das experiências dos homens, ao passo que eram negadas quando diziam respeito às condições peculiares de opressão e violência de gênero, vivida pelas mulheres. Ainda segundo Crenshaw, quando as mulheres eram

\footnotetext{
${ }^{9}$ CRENSHAW, Kimberle. Documento para o encontro de especialistas em aspectos da discriminação racial relativos ao gênero. Rev. Estud. Fem. 2002, vol.10, n.1. Disponível em: http://www.scielo.br/scielo.php?pid=S0104$\underline{026 X 2002000100011 \& \text { script }=\text { sci abstract\&tlng }}$ $=\mathrm{pt}$.

${ }^{10}$ CRENSHAW, Kimberle. Documento para o encontro de especialistas em aspectos da discriminação racial relativos ao gênero. Rev. Estud. Fem. 2002, vol.10, n.1. Disponível em:
}

vítimas de tortura ou tinham direitos civis ou políticos negados, de forma semelhante ao que acontecia com os homens, havia o reconhecimento da violação de direitos humanos. "Porém, quando mulheres, sob custódia, eram estupradas, espancadas no âmbito doméstico ou quando alguma tradição lhes negava acesso à tomada de decisões, suas diferenças em relação aos homens tornavam tais abusos periféricos em se tratando das garantias básicas dos direitos humanos". ${ }^{11}$

É nesse contexto de realidade histórica que Boaventura de Souza Santos afirma: "a política dos direitos humanos é basicamente uma política cultural". E alerta para a necessidade de superar o debate sobre universalismo na discussão acerca dos direitos humanos, não no sentido, por óbvio, de negar direitos, mas de se reconhecer também o direito à diferença, o reconhecimento de culturas distintas, que "possuem

http://www.scielo.br/scielo.php?pid=S0104026X2002000100011\&script=sci_abstract\&tlng $=\mathrm{pt}$.

${ }^{11}$ CRENSHAW, Kimberle. Documento para o encontro de especialistas em aspectos da discriminação racial relativos ao gênero. Rev. Estud. Fem. 2002, vol.10, n.1. Disponível em: http://www.scielo.br/scielo.php?pid=S0104026X2002000100011\&script=sci_abstract\&tlng $\equiv \mathrm{pt}$. 
diferentes concepções de dignidade humana" $"$. Significa, ainda, reconhecer o multicultural e o diverso e, portanto, ampliar a discussão acerca da abrangência dos direitos humanos. Questionar o discurso de universalismo, na esteira do pensamento de Boaventura de Souza Santos, significa também dar visibilidade às diferenças de raça e de gênero dentro do campo jurídico internacional de defesa dos direitos das mulheres. O que está no cerne é a percepção de que as mulheres não compõem um conjunto homogêneo e uniforme de sujeitos; ao contrário, são marcadas pelas diversidades raciais, étnicas e culturais como um todo e vivenciam de maneiras diferentes as muitas formas de opressão e violência. Como abranger essa complexidade, considerando apenas um conceito de igualdade formal que situa todas as mulheres em um campo supostamente uniforme de experiência da vida social?

A resposta a esse questionamento está justamente na dimensão política da construção dos direitos humanos das mulheres, pois a positivação da

12 SANTOS, Boaventura de Sousa. Por uma concepção multicultural de direitos humanos. Revista Crítica de ciência sociais, $\mathrm{n}^{\circ} 48$, junho/1997.
Disponível

em: igualdade de gênero nasceu dos movimentos feministas e teve desdobramentos de ordem política e normativa, ampliando as perspectivas em torno da defesa dos direitos das mulheres. Esse movimento de construção legislativa internacional verificado na história dos direitos humanos das mulheres favorece $\mathrm{O}$ entendimento de que é preciso ir além das abstrações generalizantes de direitos humanos supostamente universais, para contemplar, por meio de outras normas internacionais e internas -, as condições peculiares das vivências femininas, num mundo marcado pela dominação masculina.

A igualdade de gênero, posta como parâmetro para a fruição dos direitos humanos na Declaração Universal, abriu caminhos para a Convenção para a Eliminação de Todas as Formas de Discriminação contra as Mulheres (Convention for the Elimination of All Forms os Discrimination Against Women/CEDAW, 1979), que define, em seu art. $1^{\circ}$, como discriminação contra as

http://www.boaventuradesousasantos.pt/media/p dfs/Concepcao_multicultural_direitos humanos RCCS48.PDF. 
mulheres "toda a distinção, exclusão ou restrição baseada no sexo e que tenha por objeto ou resultado prejudicar ou anular o reconhecimento, gozo ou exercício pela mulher". ${ }^{13}$

Em 1994, o Brasil foi palco da construção da Convenção Interamericana para Prevenir, Punir e Erradicar a Violência Contra a Mulher (Convenção de Belém do Pará), norma de direitos humanos das mulheres, promulgada por meio do Decreto $\mathrm{n}^{\mathrm{o}}$ 1.973 , de $1^{\circ}$ de agosto de 1996. Somente em 2002 foi promulgada a Convenção para a Eliminação de Todas as Formas de Discriminação contra as Mulheres, por meio do Decreto $\mathrm{n}^{\circ} 4.377$, de 13 de setembro de 2002.

Com as duas Convenções, o princípio do tratamento igual para todos e todas perante a lei, disposto na Declaração Universal, ganha novos contornos. Aqui se trata de fugir do androcentrismo explícito nas declarações de direitos humanos e discutir, de fato, a problemática da questão de gênero. Assim, os estudos sobre gênero e direitos humanos

${ }^{13}$ ONU. Convenção para a Eliminação de Todas as Formas de Discriminação contra as Mulheres, 1979. passaram a enfatizar o exercício da cidadania feminina, traçar caminhos para a ampliação dos direitos humanos das mulheres, o enfrentamento à violência, $\mathrm{o}$ acesso à justiça, entre outros, além de modo a compor um sistema de justiça internacional acessível e receptivo às demandas femininas.

As duas Convenções sobre as mulheres, uma vez promulgadas no Brasil, abriram caminhos para a criação da Lei Maria da Penha (Lei n ${ }^{\circ} 11.340$, de 7 de agosto de 2006) - resultado de um litígio internacional na Corte Interamericana de Direitos Humanos - e da Lei do Feminicídio (Lei no ${ }^{\circ} 13.104$, de 9 de março de 2015), que alterou o art. 121 do Decreto-Lei n- 2.848, de 7 de dezembro de 1940 (Código Penal), para prever o feminicídio como circunstância qualificadora do crime de homicídio considerando resultar de violência doméstica ou familiar, ou por menosprezo ou discriminação à condição de mulher - , e o art. $1^{\underline{o}}$ da Lei n⿳ 8.072 , de 25 de julho de 1990, para incluir o feminicídio no rol dos crimes 
hediondos. Assim, começa a se consolidar, no Brasil, um cenário jurídico de proteção às mulheres, sobretudo daquelas em situação de violência, o que implicou modificações nas estruturas de acolhimento e de investigação, por meio das Delegacias Especializadas de Atendimento às Mulheres (DEAM), bem como nas estruturas judiciárias, com a criação dos Juizados de Violência Doméstica contra a Mulher.

Tudo isso representou mudanças nos paradigmas de enfrentamento às diversas formas de violência contra as mulheres, tanto pela abrangência dos tipos estabelecidos pela Lei Maria da Penha - violência física, sexual, moral, psicológica e patrimonial -, como pela estruturação do que se pode definir como uma justiça de gênero, ou seja, um aparato legal e institucional preparado para lidar especificamente com as questões próprias da violência contra as mulheres.

\footnotetext{
${ }^{14}$ CRENSHAW, Kimberle. Documento para o encontro de especialistas em aspectos da discriminação racial relativos ao gênero. Rev. Estud. Fem. 2002, vol.10, n.1. Disponível em: http://www.scielo.br/scielo.php?pid=S0104$\underline{026 \times 2002000100011 \& \text { script }=\text { sci_abstract\&tlng }}$ $=\mathrm{pt}$.
}

Em que pese a composição de um quadro de normas voltadas para a proteção humanitária das mulheres, é preciso, ainda e sempre, questionar o discurso de universalidade dos direitos humanos, mesmo quando estamos diante da proteção aos direitos humanos das mulheres, no sentido de ampliar a discussão acerca dos direitos decorrentes dos mais diversos tratados internacionais, pois, como afirma Crenshaw, "os aspectos raciais da discriminação de gênero não são totalmente apreendidos pelos discursos dos direitos humanos"14.

É o reconhecimento da necessidade de se observar uma perspectiva não homogênea nas experiências históricas das mulheres e dos impactos do racismo nas vidas das mulheres negras que se ampara a interseccionalidade proposta por Crenshaw, que busca dar visibilidade para aquelas racialmente marginalizadas ${ }^{15}$, de modo a permitir um avanço qualitativo no entendimento dos

${ }^{15}$ CRENSHAW, Kimberle. Documento para o encontro de especialistas em aspectos da discriminação racial relativos ao gênero. Rev. Estud. Fem. 2002, vol.10, n.1. Disponível em: http://www.scielo.br/scielo.php?pid=S0104026X2002000100011\&script=sci abstract\&tlng $=\mathrm{pt}$. 
mecanismos que reproduzem as desigualdades sociais $^{16}$. Isso porque a condição racial não se aparta das desigualdades de classe; ao contrário, caminham juntas e carregam consigo os traços de opressão e violência vividos por pessoas negras em todo o mundo e, de forma bastante peculiar, pelas mulheres negras, cujos corpos são historicamente objetificados e hiperssexualizados.

Assim, a condição racial, na compreensão dos direitos humanos das mulheres, não pode ser tomada apenas como um elemento a mais de análise ou um apêndice nos estudos. É preciso que a raça seja central, considerando 0 legado cultural das práticas de escravidão no Brasil, cuja miscigenação se deu por meio de violência contra as mulheres, sobretudo violência sexual. Por isso, as convenções de direitos humanos voltadas para as mulheres, em que pese terem representado um imenso avanço no campo da construção da igualdade de gênero, ainda não atendiam às demandas de reconhecimento de

16 MIGUEL, Luis Felipe; BIROLI, Flávia. Feminismo e política: uma introdução. 1.ed. São Paulo: Boitempo, 2014, p. 9.

${ }^{17}$ CRENSHAW, Kimberle. Documento para o encontro de especialistas em aspectos da violências específicas decorrentes da condição racial das mulheres, o que apenas se concretiza se, no campo das normas humanitárias internacionais, é feita uma interpretação sistemática e interseccional, com amparo na Convenção Internacional para a Eliminação de Todas as Formas de Discriminação Racial (1963), que trata, especificamente, da "proteção contra a discriminação baseada na cor, na descendência, e na origem étnica ou nacional"17. Essa convenção foi promulgada pelo Estado brasileiro por meio do Decreto n. ${ }^{\circ} 65.810$, de 8 de dezembro de 1969.

Uma interpretação dos direitos humanos, com a devida atenção ao racismo foi resultado do protagonismo dos mais diversos movimentos sociais, entre os quais se destacam a luta pelos direitos civis e políticos do movimento negro nos EUA, a luta contra o Apartheid na África do Sul, o fim dos regimes coloniais nos países africanos, pois assim "reconheceu-se que as instituições, práticas administrativas e estruturas

discriminação racial relativos ao gênero. Rev. Estud. Fem. 2002, vol.10, n.1. Disponível em: http://www.scielo.br/scielo.php?pid=S0104026X2002000100011\&script=sci_abstract\&tlng $=\mathrm{pt}$. 
políticas e sociais podiam agir de maneira adversa e racialmente discriminatória ou excludente"18.

Assim, na Declaração Universal dos Direitos Humanos, "a incorporação da dimensão igualitária dos Direitos Humanos afirma, que todos os seres humanos são livres e iguais"19 e estabelece a especificação das práticas de discriminação racial, de modo a colaborar para a "determinação mais concreta dos destinatários da tutela jurídica dos direitos e garantias individuais" $"$ agregando "novos elementos ao conteúdo dos direitos humanos"21. Esses elementos garantem uma maior amplitude para as elaborações sobre direitos humanos e, ao mesmo tempo, enriquecem a análise, fugindo de um universalismo abstrato dos princípios estabelecidos nos tratados internacionais. Tal aspecto, inclusive, favorece a defesa da dignidade da pessoa

${ }^{18}$ SANTOS, Ivair Augusto Alves dos. Direitos Humanos e as práticas de racismo: o que faremos com os brancos racistas?. Tese de Doutorado em sociologia da UNB, 2009. Disponível em: http://repositorio.unb.br/handle/10482/5276.

${ }^{19}$ SANTOS, Ivair Augusto Alves dos. Direitos Humanos e as práticas de racismo: o que faremos com os brancos racistas?. Tese de Doutorado em sociologia da UNB, 2009. Disponível em: http://repositorio.unb.br/handle/10482/5276. humana, princípio que fundamenta $\mathrm{o}$ estado democrático de direito.

No Brasil, a crença em uma suposta democracia racial e num processo de construção harmônica das relações raciais aparece como um impedimento para a análise do racismo na sociedade brasileira. A invisibilidade do racismo em uma sociedade majoritariamente negra e na qual as mulheres negras representam a maioria das vítimas de feminicídio, é fruto de uma crença em um processo de miscigenação "pacífica", que tem por intenção esconder as práticas desumanas da escravidão, especialmente da violência, não apenas física, mas sexual, dirigida contra as mulheres negras e das consequências nefastas desse período, mesmo após a abolição da escravidão no País. Portanto, "o governo brasileiro, embora tenha sido um dos primeiros a adotar a Convenção [Internacional para a

${ }^{20}$ SANTOS, Ivair Augusto Alves dos. Direitos Humanos e as práticas de racismo: o que faremos com os brancos racistas?. Tese de Doutorado em sociologia da UNB, 2009. Disponível em: http://repositorio.unb.br/handle/10482/5276.

${ }^{21}$ SANTOS, Ivair Augusto Alves dos. Direitos Humanos e as práticas de racismo: o que faremos com os brancos racistas?. Tese de Doutorado em sociologia da UNB, 2009. Disponível em: http://repositorio.unb.br/handle/10482/5276. 
Eliminação de Todas as Formas de Discriminação Racial], não se via à vontade em responder a ONU, porque não se via como um país onde a discriminação racial fosse uma prática" 22 .

Quando se compreende como o racismo opera nas sociedades, a partir do exemplo do Brasil, é possível afastar a percepção abstrata e universalista dos direitos humanos, no sentido de entender que observar as diferenças não significa segregar e negar direitos, mas sim ampliar o campo de percepção das desigualdades sociais e, assim, melhor defender os direitos de homens e mulheres. $\mathrm{O}$ racismo não é uma questão biológica. Ao contrário, é na dimensão da cultura que se encontram os elementos históricos para a percepção do racismo como uma prática social ainda muito presente na realidade brasileira. A raça, como perspectiva de análise e estudo, segundo Passos, é a compreensão, no Brasil de "uma

${ }^{22}$ SANTOS, Ivair Augusto Alves dos. Direitos Humanos e as práticas de racismo: o que faremos com os brancos racistas?. Tese de Doutorado em sociologia da UNB, 2009. Disponível em: http://repositorio.unb.br/handle/10482/5276. 23 PASSOS, Joana Célia; ROSA, Stela. Violências de gênero e racismo. In: Ana Maria Veiga; Teresa Kleba Lisboa e Cristina Scheibe construção histórica, política, cultural e social que se reproduz nas relações de poder brasileiras. Portanto, não se trata de falar de uma existência biológica, mas de falar sobre práticas sociais racializadas e racistas" que permeiam a sociedade brasileira e o imaginário social $^{23}$.

Para Flávia Piovesan, é "insuficiente tratar o indivíduo de forma genérica, geral e abstrata. Faz-se necessário a especificação do sujeito de direito, que passa a ser visto em sua peculiaridade e particularidade. Nessa ótica, determinados sujeitos de direitos, ou determinadas violações de direitos, exigem uma resposta específica e diferenciada" ${ }^{24}$. Isso porque, na esfera internacional, segundo a autora, se a vocação inicial de instrumentos internacionais é proporcionar uma proteção geral, genérica e abstrata - o que pode significar o próprio temor à diferença -, surge, posteriormente, a necessidade de conferir proteção

\footnotetext{
Wolff (Org.). Gênero e violências: diálogos interdisciplinares. Edições do Bosque/CFH/UFSC, 2016 - (Série Diversidades), p. 49.

${ }^{24}$ PIOVESAN, Flávia. Ações afirmativas e direitos humanos. Revista USP, $n^{\circ} 69$ (2006). Disponível em: http://www.revistas.usp.br/revusp/issue/view/10 70.
} 
especial e particularizada a determinados grupos, diante de sua própria vulnerabilidade. Então, a diferença não seria um meio para a aniquilação de direitos, mas sim para a promoção de direitos. E afirma: "Nesse cenário, por exemplo, a população afrodescendente, as mulheres, as crianças e demais grupos devem ser vistos nas especificidades e peculiaridades de sua condição social. Ao lado do direito à igualdade, surge, também, como direito fundamental, o direito à diferença. Importa o respeito à diferença e à diversidade, o que lhes assegura um tratamento especial" 25 .

Entender os processos históricos de desigualdades e violências experimentadas pelas mulheres negras e marginalizadas no Brasil e desvelar, conforme pontua o sociólogo Pierre Bourdieu, os processos de "deshistoricização do feminino e a eternização do arbitrário"26, é um processo que só encontra sentido quando o racismo, nas análises sobre violações dos direitos humanos, é considerado em sua relevância socio-histórica e política.

25 PIOVESAN, Flávia. Ações afirmativas e direitos humanos. Revista USP, no 69 (2006). Disponível em: http://www.revistas.usp.br/revusp/issue/view/10 70 .
Esse processo, longe de tornar invisível outras mulheres, contribui para a compreensão das raízes da questão racial no Brasil, de modo a desvendar seu desenvolvimento histórico e colaborar para a elaboração de políticas públicas por parte dos Estados que, de fato, possam dar conta de complexidade que envolve o tema. Evidenciar o papel que o racismo tem na vida das mulheres negras, ao observar as violações aos direitos humanos na violência de gênero, significa colocar em protagonismo a vida das mulheres negras, com o intuito de proporcionar uma existência digna, minimizando as muitas violências, reais e simbólicas que acompanham as histórias de suas vidas.

Tão importante quanto a Declaração Universal dos Direitos Humanos de 1948 são as normas dela advindas, mais especificamente as normas regulamentadoras da Declaração, quais sejam, o Pacto Internacional sobre Direitos Econômicos, Sociais e Culturais (PIDESC) e o Pacto Internacional dos

26 BOURDIEU, Pierre. A Dominação Masculina. Rio de Janeiro: $4^{\circ}$ Ed. Editora Bertrand Brasil, 2005. Prefácio à edição alemã. 
Direitos Civis e Políticos (PIDCP). Esses documentos, como reguladores dos princípios elencados na Declaração de 1948, foram de suma importância para traçar junto aos Estados formas de garantir a efetivação dos direitos humanos. Nesse sentido, tanto o princípio da igualdade entre os gêneros, como a exigência da não discriminação com base na raça, estão descritos e reafirmados no PIDESC como forma de se garantir um amplo debate sobre as desigualdades de gênero e racial no contexto dos direitos humanos. No entanto, as violações de direitos às quais estão submetidas a população negra, mais uma vez colocam em questionamento a materialização desses pactos. Não se trata, pois, de não compreender a importância desses tratados, mas de se observar as práticas institucionais no Brasil que mascaram o racismo.

O Brasil é signatário da Convenção para a Eliminação de Todas as Formas de Discriminação Racial, mas parece estar longe de garantir dignidade a negros e negras, o que se

${ }^{27}$ SANTOS, Ivair Augusto Alves dos. Direitos Humanos e as práticas de racismo: o que faremos com os brancos racistas?. Tese de evidencia, entre outros fatores, pelos altos índices de violência contra as mulheres negras. $\mathrm{O}$ primeiro relatório brasileiro sobre racismo no Brasil foi considerado, pelo Comitê avaliador da Convenção para a Eliminação de Todas as Formas de Discriminação Racial, como insatisfatório, pois "o governo brasileiro não respondia a nenhum dos artigos da Convenção, era um texto que trabalhava com o senso comum de não haver discriminação racial no Brasil e, portanto, não precisaria ter medidas para combater o racismo ${ }^{27 "}$. Tal resposta, assim como as evidências empíricas sobre a violência destinada principalmente à população negra, e a consequente vulnerabilidade de negros e negras no País, demonstram a necessidade de uma leitura interseccional da realidade.

Nas palavras de Thula Pires, a violação aos direitos humanos das mulheres negras corresponde, em última instância, "a uma noção de direitos humanos não comprometida com a emancipação dos seres concretos e plurais, demonstrando a falácia do

Doutorado em sociologia da UNB, 2009. Disponível em: http://repositorio.unb.br/handle/10482/5276. 
discurso de universalidade" 28 e "a proposta de universalização de forma retórica mascara e naturaliza relações sociais de dominação, opressão e de sistemática ofensa à integridade, cultura e memória do outro"29. Assim, é possível perceber o que de fato se esconde por trás de um discurso universalista nas construções sociais sobre direitos humanos: um universalismo que na verdade mascara diferenças que precisam ser reconhecidas para se combater a exclusão social, a exemplo daquelas às quais as mulheres negras estão submetidas no Brasil.

\section{Um Breve Panorama Sobre A} Violência Intencional No Brasil: Uma Análise A Partir Da Perspectiva Racial E De Gênero

Os dados sobre as violências direcionadas as mulheres no Brasil, para

\footnotetext{
${ }^{28}$ PIRES, Thula Rafaela de Oliveira; BERNER, Vanessa Oliveira Batista; FRANÇA, Júlia Monteath de. Os estudantes africanos no Brasil na perspectiva da teoria crítica dos direitos humanos. Quaestio Iuris, vol. 9, $\mathrm{n}^{\circ}$ 2, Rio de Janeiro, 2016. Disponível em: http://www.epublicacoes.uerj.br/index.php/quaestioiuris/artic le/view/18703.

${ }^{29}$ PIRES, Thula Rafaela de Oliveira; BERNER, Vanessa Oliveira Batista; FRANÇA, Júlia Monteath de. Os estudantes africanos no Brasil na perspectiva da teoria crítica dos direitos
}

além de representar um quadro de profunda desigualdade nas relações de gênero, evidenciam, também, um panorama de desníveis sociais que precisa ser considerado para além dos dados em si. A breve análise de dados aqui realizada se baseará em relatório do Instituto de Pesquisa Econômica Aplicada (IPEA) e do Fórum Brasileiro de Segurança Pública, denominado “Atlas da violência 2018”, e de relatório recente do IPEA denominado "Mortalidade de Mulheres por agressões no Brasil: perfil e estimativas corrigidas (2011-2013)".

O Atlas da Violência de 2018 revelou que, apenas em 2016, foram assassinadas 4.645 mulheres no Brasil. Segundo o relatório, houve um aumento de pelo menos $6,4 \%$ desse tipo de crime entre 2006 e $2016^{30}$. No entanto, nesse mesmo ano, as taxas de mortes de mulheres negras foram ainda mais

humanos. Quaestio Iuris, vol. 9, no 2, Rio de Janeiro, 2016. Disponível em: http://www.epublicacoes.uerj.br/index.php/quaestioiuris/artic le/view/18703.

30 IPEA, Instituto de Pesquisa Econômica Aplicada; FBSP, Fórum Brasileiro de Segurança Pública. Atlas da violência 2018. Rio de Janeiro, junho de 2018. Disponível em: http://www.ipea.gov.br/portal/index.php?option $=$ com_content $\& v i e w=$ article $\& i d=33410 \&$ Itemi $\mathrm{d}=432$. 
elevadas. Segundo o Atlas, no período compreendido entre 2006 e 2016, a taxa de morte de mulheres negras aumentou em média 15,4\%, enquanto, nesse mesmo período, a taxa de mortalidade de mulheres não negras sofreu uma queda de $8 \%$.

Os dados sobre feminicídios no Brasil ainda são muito frágeis e isso acontece por inúmeros fatores. No entanto, pode-se destacar a fragilidade dos registros de notificação por parte dos órgãos de segurança pública ou do sistema penal. Segundo o relatório "Mortalidade de Mulheres por agressões no Brasil" do IPEA, que fez uma estimativa entre os anos de 2011 e 2013, nesse período ocorreram, no Brasil, 5.860 mortes de mulheres por agressões $^{32}$. De acordo com o IPEA, este dado corresponde, em média, entre os anos de 2011 e 2013, a 488 mortes a cada mês, 16 a cada dia ou uma morte a cada

31 IPEA, Instituto de Pesquisa Econômica Aplicada; FBSP, Fórum Brasileiro de Segurança Pública. Atlas da violência 2018. Rio de Janeiro, junho de 2018. Disponível em: http://www.ipea.gov.br/portal/index.php?option $=$ com_content $\&$ view $=$ article $\&$ id=33410\&Itemi $\mathrm{d}=432$.

32 IPEA, Instituto de Pesquisa Econômica e Aplicada, Brasília. Mortalidade de Mulheres por agressões no Brasil: perfil e estimativas corrigidas (2011-2013). Rio de Janeiro, 2016. uma hora e meia ${ }^{33}$. Os dados trazidos pelo IPEA revelam o tamanho das violações aos direitos humanos das mulheres no Brasil, o que aponta para uma grave falha do Estado em proteger a vida das mulheres brasileiras, mesmo com a Lei 11.340/06, conhecida como Lei Maria da Penha, que prevê um conjunto de políticas públicas e medidas judiciais de caráter preventivo.

Segundo o relatório do IPEA, “o decréscimo nas taxas de homicídio no ano de aplicação da Lei Maria da Penha e o subsequente aumento dessas mesmas taxas nos anos seguintes indica que as políticas atuais necessitam de constante avaliação para a efetiva redução do quadro de violação dos direitos das mulheres", o que significa dizer que a Lei Maria da Penha por si só não tem o condão de diminuir esses índices e que as políticas públicas estatais são fundamentais para a prevenção a essa

Disponível

em: http://www.ipea.gov.br/portal/index.php?option $=$ com_content $\&$ view=article $\& i d=27250$.

33 IPEA, Instituto de Pesquisa Econômica e Aplicada, Brasília. Mortalidade de Mulheres por agressões no Brasil: perfil e estimativas corrigidas (2011-2013). Rio de Janeiro, 2016. Disponível em: http://www.ipea.gov.br/portal/index.php?option $=$ com_content $\&$ view=article $\&$ id $=27250$. 
forma de violência. A Lei Maria da Penha não é exclusivamente uma lei penal, pois apresenta um vasto conjunto de possibilidades de intervenção preventiva, o que envolve aspectos de educação em direitos e para a igualdade, bem como o acompanhamento do agressor, na tentativa de evitar a reincidência e o agravamento de violências de natureza doméstica, com vistas a reduzir as taxas de feminicídio.

Os dados do IPEA revelam que, no período avaliado, correspondente aos anos de 2011 e 2013, o padrão racial continua e pelo menos $64 \%$ das mulheres assassinadas são negras, em sua maioria mulheres adolescentes e jovens na faixa etária entre 10 e $29 \operatorname{anos}^{34}$. Percebe-se que o padrão racial nas vítimas de feminicídio vem se repetindo tanto no ano de 2016, avaliado pelo Atlas da Violência, como nos períodos anteriores, avaliados pelo IPEA. No estudo sobre mortalidade de mulheres por agressões,

34 IPEA, Instituto de Pesquisa Econômica e Aplicada, Brasília. Mortalidade de Mulheres por agressões no Brasil: perfil e estimativas corrigidas (2011-2013). Rio de Janeiro, 2016. Disponível em: http://www.ipea.gov.br/portal/index.php?option $=$ com_content $\&$ view $=$ article $\&$ id $=27250$.

35 IPEA, Instituto de Pesquisa Econômica e Aplicada, Brasília. Mortalidade de Mulheres por agressões no Brasil: perfil e estimativas as mulheres negras são o principal alvo

da violência feminicida no Brasil.

É importante considerar que o feminicídio significa, por óbvio, um estágio final de uma série de violências às quais as mulheres - especialmente mulheres negras, como demonstrado nos relatórios - estão submetidas. Trata-se de um problema tão grave que, no último período, a Organização Mundial da Saúde (OMS) o coloca como um problema de saúde pública ${ }^{35}$ :

Segundo a OMS (Organização Mundial da Saúde), esse tipo de violência pode afetar a saúde de diversas formas, que incluem gravidezes indesejadas, abortos induzidos, problemas ginecológicos e doenças transmissíveis. Também está associada a maior probabilidade de aborto, perda fetal, parto pré-termo e baixo peso ao nascer. Essas formas de violência podem causar depressão, problemas de sono, distúrbios alimentares e outras formas de transtornos mentais, como abuso de álcool e outras drogas. Com grande frequência, a violência doméstica é causa de lesões, reportadas por $42 \%$ das mulheres como consequência desse tipo de violência. Por fim, pode ter consequências fatais, como homicídios e suicídios ${ }^{36}$.

corrigidas (2011-2013). Rio de Janeiro, 2016. Disponível em: http://www.ipea.gov.br/portal/index.php?option $=$ com_content $\&$ view $=$ article $\& i d=27250$.

36 IPEA, Instituto de Pesquisa Econômica e Aplicada, Brasília. Mortalidade de Mulheres por agressões no Brasil: perfil e estimativas corrigidas (2011-2013). Rio de Janeiro, 2016. Disponível em: 
Evidenciar a perspectiva racial nesses dados não significa relativizar o feminicídio no Brasil ou criar algum tipo de dicotomia, mas destacar que o racismo, longe de ser apenas um elemento ou uma variável a mais de risco na vida dessas mulheres, precisa ser encarado como um fator central nos estudos sobre o tema. Nesse sentido, significa dizer que no Brasil não é possível falar sobre direitos humanos para as mulheres e de igualdade, como enunciado pela Declaração Internacional de Direitos Humanos, sem falar do lugar ocupado pelo racismo na sociedade brasileira.

\section{Conclusão}

A positivação da igualdade entre homens e mulheres na esfera jurídica internacional foi uma das maiores conquistas civilizatórias da humanidade. No entanto, é preciso reconhecer que não se tratou de uma construção naturalizada entre todas as nações. Ao contrário, resultou das reivindicações dos diversos movimentos feministas, atentos às muitas opressões e violências que resultam das desigualdades de gênero que invisibilizaram as mulheres e suas histórias plurais, marcadas, principalmente, por diferenças raciais constantemente ignoradas nas dinâmicas sociais, na ciência e nas políticas públicas.

As reflexões aqui apresentadas tiveram por finalidade fazer uma discussão sobre a Declaração Universal dos Direitos Humanos de 1948, para delinear como essa norma internacional, ao tratar sobre a proteção igual de todos e todas perante a lei, sem qualquer discriminação, foi fundamental para estabelecer o princípio da igualdade entre os gêneros e trouxe novas perspectivas para a defesa dos direitos humanos das mulheres no mundo.

Embora se reconheça a importância da Declaração para a construção de todo o sistema de proteção aos direitos humanos - e, nesse caso, dos direitos humanos das mulheres posteriormente tornou-se evidente a necessidade de se questionar o discurso universalista que escondia a diversidade 
étnica presente na concepção sobre direitos humanos.

Ainda por força dos movimentos feministas, o gênero passa a ser o foco de novas construções normativas humanitárias, o que culminou com a Convenção pela Eliminação de Todas as Formas de Discriminação contra a Mulher e a Convenção Interamericana para Prevenir, Punir e Erradicar a Violência contra a Mulher, conhecida como Convenção de Belém do Pará.

Se por um lado essas convenções atenderam à necessidade de construir um campo jurídico de proteção aos direitos humanos das mulheres, fugindo do universalismo típico das normas generalizantes e andróginas, por outro lado os movimentos feministas negros também passaram a reivindicar atenção à condição racial e étnica das mulheres, de modo que a perspectiva de gênero passasse a ser fortalecida por uma aproximação às condições de raça e classe, de modo a abranger a diversidade e multiculturalidade nos seus mais diversos aspectos. Nesse sentido é que se defendeu aqui uma análise interseccional da violência letal contra as mulheres, que coloque a condição racial interligada às questões de gênero, o que se alcança, em termos de aproximação normativa no cenário jurídico internacional, pela interpretação sistemática da Convenção para a Eliminação de Todas as Formas de Discriminação Racial com as demais normas internacionais protetoras dos direitos humanos das mulheres.

No Brasil, a análise interseccional é fundamental, levando-se em consideração que é contra a população negra que a violência letal é comumente dirigida, o que se evidencia pelos números de feminicídios contra mulheres negras. A análise dos índices de feminicídios indicam que as mulheres negras são alvo prioritário, o que exige muitas reflexões sobre o real significado da violência racista e de gênero.

Ao tecer considerações sobre a violência a partir dos dados sobre feminicídios no país, numa perspectiva interseccional, pretendeu-se, para além de fazer um breve panorama do caso brasileiro, destacar que as considerações sobre direitos humanos são mais complexas do que aparentam. Trata-se, aqui, de defender não apenas a necessidade de uma discussão transversal sobre o tema em todos os espaços e processos históricos, mas de 
trazer também essa transversalidade para o discurso jurídico.

Para tanto, é preciso aproximar racismo e gênero nos discursos sobre direitos humanos, no sentido de trazer à luz as experiências históricas das mulheres negras no mundo, ponto essencial que coloca em questionamento também a conformação histórica dos próprios movimentos feministas, superando, assim, uma visão supostamente homogênea na história de construção dos direitos humanos das mulheres.

\section{Referências Bibliográficas}

BOURDIEU, Pierre. A dominação masculina. Rio de Janeiro: $4^{\circ}$ Ed. Editora Bertrand Brasil, 2005.

CAMPOS, Carmen Hein de. Criminologia feminista: teoria feminista e crítica às criminologias. $1^{\circ}$ ed. - Rio de Janeiro: Lumen Juris, 2017.

COSTA, Malena. Feminismos juridicos. Ciudad Autonoma de Buenos Aires: Didot, 2016.
CRENSHAW, Kimberle. Documento para o encontro de especialistas em aspectos da discriminação racial relativos ao gênero. Rev. Estud. Fem. 2002, vol.10, n.1. Disponível em: http://www.scielo.br/scielo.php?pid=S0 $\underline{104-}$

$\underline{026 X 2002000100011 \& \text { script }=\text { sci_abstr }}$ act\&tlng=pt.

IPEA, Instituto de Pesquisa Econômica Aplicada; FBSP, Fórum Brasileiro de Segurança Pública. Atlas da violência 2018. Rio de Janeiro, junho de 2018. Disponível em: http://www.ipea.gov.br/portal/index.php ?option=com_content\&view=article $\&$ id $=33410 \&$ Itemid $=432$.

IPEA, Instituto de Pesquisa Econômica e Aplicada, Brasília. Mortalidade de mulheres por agressões no Brasil: perfil e estimativas corrigidas (20112013). Rio de Janeiro, 2016. Disponível em:

http://www.ipea.gov.br/portal/index.php ?option=com_content\&view=article\&id $=27250$.

MENDES, Soraia da Rosa.

Criminologia feminista: novos 
paradigmas. $2^{\circ}$ ed. - São Paulo: Saraiva, 2017.

MIGUEL, Luis Felipe; BIROLI, Flávia.

Feminismo e política: uma introdução.

1.ed. São Paulo: Boitempo, 2014.

\section{ONU, Convenção Internacional para a}

Eliminação de Todas as Formas de

Discriminação Racial,1963.

\section{Convenção Interamericana}

para Prevenir, Punir e Erradicar a

Violência Contra a Mulher

(Convenção de Belém do Pará), 1994.

\section{Convenção para a Eliminação}

de Todas as Formas de Discriminação contra as Mulheres, 1979.

Declaração Universal dos

Direitos Humanos, 1948.

\section{Pacto Internacional sobre}

Direitos Civis e Políticos, 1955.

Pacto Internacional sobre

Direitos Econômicos, Sociais e

Culturais, 1955.
PASSOS, Joana Célia; ROSA, Stela. Violências de gênero e racismo. In: Ana Maria Veiga; Teresa Kleba Lisboa e Cristina Scheibe Wolff (Org.). Gênero e violências: diálogos interdisciplinares. Edições do Bosque/CFH/UFSC, 2016 (Série Diversidades).

PIOVESAN, Flávia. Ações afirmativas e direitos humanos. Revista USP, $\mathrm{n}^{\text {o }} 69$ (2006). Disponível em: http://www.revistas.usp.br/revusp/issue/ view/1070.

PIRES, Thula Rafaela de Oliveira; BERNER, Vanessa Oliveira Batista; FRANÇA, Júlia Monteath de. Os estudantes africanos no Brasil na perspectiva da teoria crítica dos direitos humanos. Quaestio Iuris, vol. 9, $\mathrm{n}^{\circ}$ 2, Rio de Janeiro, 2016. Disponível em: http://www.epublicacoes.uerj.br/index.php/quaestioi uris/article/view/18703.

SANTOS, Boaventura de Sousa. Por uma concepção multicultural de direitos humanos. Revista Crítica de ciência sociais, $n^{\circ}$ 48, junho/1997. Disponível em: http://www.boaventuradesousasantos.pt/ 
$\underline{\text { media/pdfs/Concepcao_multicultural_di }}$

reitos_humanos_RCCS48.PDF.

SANTOS, Ivair Augusto Alves dos.

Direitos Humanos e as práticas de

racismo: o que faremos com os

brancos racistas?. Tese de Doutorado

em sociologia da UNB, 2009. Disponível

em:

http://repositorio.unb.br/handle/10482/5

$\underline{276}$. 